community. I'm as dependent here in Toronto on Ottawa, as Ottawa is on me and, in fact, I'm actually quite dependent on how they do it in Winnipeg as well."

The OMA and Ontario's Chief $\mathrm{MOH}$ Dr. Sheela Basrur attributes the province's woes to a chronic shortage of community medicine specialists, inadequate pay and difficult working conditions, plus an often-incoherent governance structure with confusing lines of authority and 50-50 cost-sharing (to be elevated to $75^{-25}$ in 2007) of public health between the provincial government and municipalities.

The financial load has prompted several municipalities to use a loophole in the province's Health Protection and Promotion Act to fill vacant local $\mathrm{MOH}$ posts with "part-time, acting" appointees, who often lack proper training to oversee disease outbreaks but are willing to toil for lower pay.

Basrur says existing regulations governing minimum educational credentials for local MOHs are so weak that someone with I year of postgraduate training in epidemiology, quantitative methods, administration, and disease prevention is eligible for appointment. "But I can tell you that to do anything close to the basic training in those 4 areas would take more than a year."

"Yet even with that minimum, we have trouble getting candidates," Basrur adds. - Wayne Kondro, Ottawa

DOI:I0.1503/cmaj.051633

\section{Diabetes plan considered}

$\mathrm{H}$ ealth Canada is reviewing a proposal by the Canadian Diabetes Association (CDA) for a "catastrophic drug plan" to help Canadians with diabetes "relieve the overwhelming personal out-of-pocket costs for medications, supplies and devices."

More than 2 million Canadians live with diabetes and bear out-of-pocket expenses ranging from $\$ 250$ a year in the Yukon to around $\$ 3600$ in Newfoundland, according to the CDA's Diabetes Report 2005. With a price tag estimated at $\$ 500$ million a year, the proposed national drug plan could eliminate this burden, in addition to helping with other chronic diseases.

Chris Williams, a communications officer for Health Canada, says a catastrophic drug plan is a key component in discussions around a National Pharmaceutical Strategy being developed by federal, territorial and provincial governments. Health Ministers will report on progress by June 30 .

The CDA argues that a national plan would substantially reduce the financial burden of diabetes; the condition and its complications cost Canada's health care system $\$$ I3.2 billion annually. - Andréa Ventimiglia, Ottawa

DOI:I0.1503/cmaj.060010

\section{Provinces lure physicians}

\section{from one another}

$\mathrm{P}$ rovinces and territories are continuing to compete for physicians in the absence of a national or provincially coordinated recruitment plan, says the Health Council of Canada.

In the 5-year period, 1999-2003, Newfoundland and Labrador, Quebec and Saskatchewan lost the greatest number of physicians, at 269, 263 and 263 respectively. British Columbia, Ontario and Alberta attracted the largest number of physicians, at 466, 345 and 24I respectively (see Fig. I).

The report, Modernizing the Management of Health Human Resources in Canada, sets 2-5 year targets for human resource planning for governments, professional associations, regulatory bodies, employers, unions and educators. It also recommends that initiatives be "properly resourced" and based on population health needs integrated across jurisdictions.

"The Council's emphasis is not on seeing this as a physician supply problem, but on seeing this as an organization of care problem," says Michael Decter, chair of the Council.

If a hospital loses a physician to another province, at least the organization can conduct a search to replace the doctor, Decter says. It's a much tougher problem in the community, where losing a family physician can mean the service disappears.

Creating strong organizations, such as group practices, at the primary care level means that, if a physician leaves, the organization can still look after patients and can recruit, says Decter.

Evidence suggests that the team approach to health also produces better health outcomes for patients, particularly those with chronic conditions such as diabetes, Decter says.

The Ontario Medical Association recently issued its own recommendations concerning physician shortages.

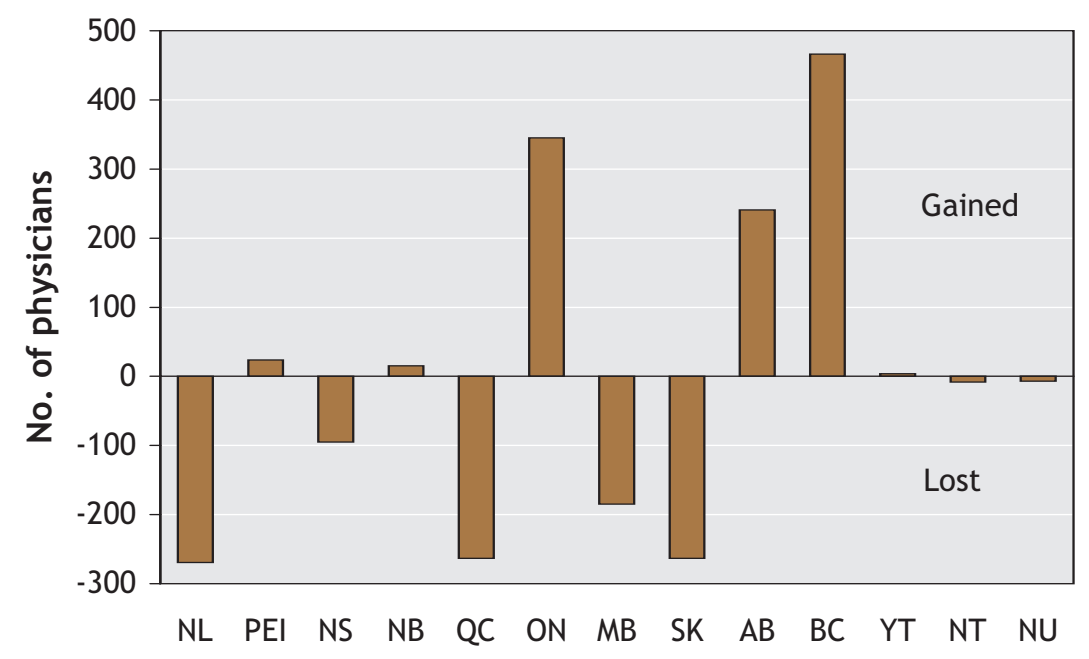

Fig. 1: Number of physicians gained or lost (Canada, 1999-2003).

Source: Canadian Institute for Health Information 
They include increasing medical school enrolment; offering incentives to retain physicians and rural doctors; temporarily increasing the number of fully qualified international medical graduates; and eliminating physician billing caps and regulations mandating forced retirement. — Laura Eggertson, $C M A J$

DOI:IO.I503/cmaj.051582

\section{Tsunami donations help}

\section{worldwide}

Published at www.cmaj.ca on Dec. 27, 2005. Revised on Jan. 5, 2006.

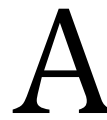
year after the tsunami that devastated Southeast Asia, Médecins Sans Frontières (MSF) reports that donors' generosity helped not only victims of that disaster, but other crises worldwide.

Donors gave \$150 million to MSF's I9 branches worldwide, including \$2.7 million to MSF Canada for emergency aid after the tsunami. It was the largest financial support the organization has received in its 30-year history, said Patrice Pagé, then executive director of MSF Canada.

Less than 2 weeks after the tsunami struck on Dec. 26, 2004, MSF made the "controversial" decision to tell donors it had received enough money - \$25 million at that point - to finance its tsunami relief operations.

Instead of refusing further donations, MSF asked for unrestricted funds to go to other emergencies, including nutritional crises in Africa.

The experiment worked; less than $\mathrm{I} \%$ of donors insisted that their money be used only for tsunami relief and the rest allowed it to go into MSF's emergency relief fund.

MSF's decision to tell donors early on that they had enough for tsunami aid was "a good idea," says Dane Rowlands, associate director of the Norman Patterson School of International Development at Ottawa's Carleton University. "It allows them enough flexibility that hopefully they will be

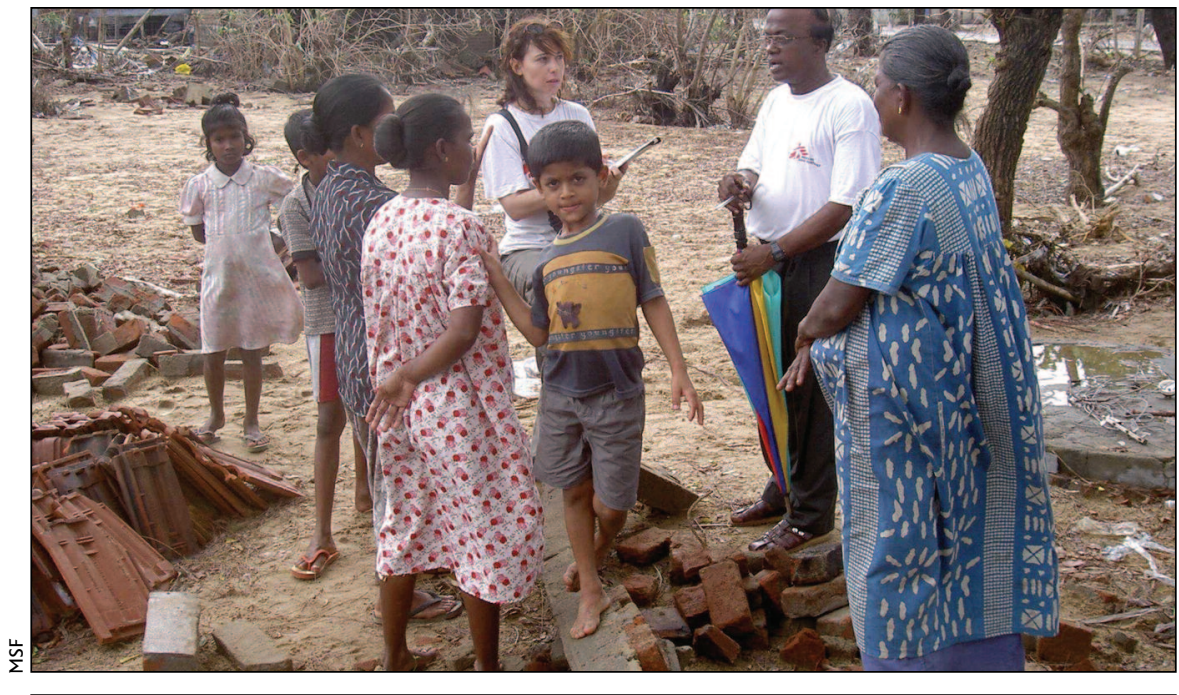

A mental health survey of displaced people in Aceh found $83 \%$ were affected by severe emotional distress.

able to make a resource allocation to less public, but high areas of need."

MSF channelled \$1.9 million of the Canadian tsunami donations to its emergency fund. That money enabled the organization to set up operations 48 hours after an earthquake devastated the Kashmir region of Pakistan on Oct. 8. MSF Canada spent just under $\$ 2$ million responding to the earthquake and \$r.6 million in providing emergency assistance in the Congo. The organization also sent teams and assistance to Darfur, Sudan, to Chad, and to Niger, where by the end of the year MSF expects to have treated more than 50 ooo undernourished children.

MSF's account of how it spent its money was also important, says Rowlands. Over the years, NGOs have demanded that other institutions be more transparent, now that demand is being made of them.

In responding to the tsunami, which killed an estimated 300 ooo people, MSF focused its efforts in Aceh, Indonesia. By the end of 2006, the organization will have spent $\$ 800$ ooo of the Canadian contributions on its Aceh operations.

Initially, MSF concentrated on primary health care, including vaccinations and tetanus shots, and supplied nurses and other medical staff to the public health structure to replace hundreds of health workers who died.

Now the organization is concentrating on mental health consultations.
"People are still deeply affected, not only by the consequences of the tsunami, but also because of the consequences of the [civil] conflict there," says Pagé. — Laura Eggertson, CMAJ

DOI:I0.1503/cmaj.051642

\section{Wait-time benchmarks}

\section{fall short}

$\mathrm{N}$ ew wait-time benchmarks announced Dec. 12 by the federal government were both lauded as a major shift in health care delivery and criticized for failing to set deadlines for implementation.

The announcement fulfils a promise made in the September 2004 federal/ provincial health accord to establish "evidence-based wait-time benchmarks" in 5 areas of care. The benchmark targets in all jurisdictions (except Quebec, which will develop its own plan) include: cancer radiation treatment within 4 weeks, hip fracture repair within 48 hours, hip and knee replacement surgery within 6 months, cataract surgery within 4 months for high-risk patients, breast cancer screening for women 50 to 69 every 2 years, cervical cancer screening for women I8 to 69 every 3 years; and cardiac bypass surgery within 2 to 6 weeks for those at high risk. 